\title{
Energy-efficient converters for electric vehicle charging stations
}

\author{
Gowthamraj Rajendran $^{1}$ (D) Chockalingam Aravind Vaithilingam ${ }^{1} \cdot$ Kanendra Naidu $^{2}$. \\ Kameswara Satya Prakash Oruganti ${ }^{1}$
}

Received: 6 December 2019 / Accepted: 27 February 2020 / Published online: 9 March 2020

(c) Springer Nature Switzerland AG 2020

\begin{abstract}
The rise in the number of electric vehicles used by the consumers is shaping the future for a cleaner and energy-efficient transport electrification. The commercial success of electric vehicles (EVs) relies heavily on the presence of high-efficiency charging stations. This article reviews the design and evaluation of different AC/DC converter topologies of the present status and future implementation plans for DC fast-charging infrastructures. The design and evaluation of these converters are presented, analysed, and compared in terms of output power, component count, power factor, and total harmonic distortion effectiveness and reliability. This paper also evaluates the architecture, merit, and demerits of AC/ DC converter topologies for DC fast-charging stations. Based on this analysis, it has found that the Vienna rectifier is the best suitable converter topology for the high-power DC fast-charging infrastructure $(>20 \mathrm{~kW})$, thanks to its low current ripples, low output voltage ripples, high efficiency, high power density, and high reliability. The paper focuses specifically on different topologies of Vienna rectifier topologies on Level-3 DC fast-charging stations which direct to less $\mathrm{CO}_{2}$ emissions in electric vehicle charging stations, thus contributing to sustainable development goals of climatic action.
\end{abstract}

Keywords Electric vehicles · Charging stations · Vienna rectifier · Total harmonic distortion · Power factor

\section{List of symbols}

$I_{D_{\text {avg }}} \quad$ Diode average current $(A)$

$\hat{l}_{N} \quad$ Peak phase current $(A)$

$I_{D_{\text {RMS }}} \quad$ Diode RMS current $(A)$

$I_{S_{\text {avg }}} \quad$ Average switching current (A)

$I_{S_{\text {RMS }}} \quad$ RMS switching current (A)

$I_{C_{\text {out RMS }}}$ Capacitor output RMS current (A)

$V_{f} \quad$ Forward voltage $(\mathrm{v})$

$f_{\mathrm{sw}} \quad$ Switching frequency $(\mathrm{Hz})$

$t_{\mathrm{f}} \quad$ Fall time (s)

$t_{\mathrm{r}} \quad$ Rise time (s)

\section{Introduction}

In the transportation electrification, the pure electric vehicles (EVs) are becoming an emerging technology and power sector because of their zero emission [1]. The interest in increasing the EVs running on alternate and renewable sources of energy has led to a spurt of research in the direction of improving the technologies involved in the EVs [2-4]. Various initiatives have been undertaken by several government organizations across the globe along with the improvement of these EV technologies to push for the usage of vehicles which run on alternate source of energy. Various organizations, such as IEEE, the Society of Automotive Engineers (SAE), and the Infrastructure Working Council (IWC) are preparing standards and codes concerning the utility/customer interface. To electrifying

Chockalingam Aravind Vaithilingam, aravindcv@ieee.org; chockalingamaravind.vaithilingam@taylors.edu.my $\left.\right|^{1}$ High Impact Research Lab, Faculty of Innovation and Technology, Taylor's University Lakeside Campus, 47500 Subang Jaya, Selangor, Malaysia. ${ }^{2}$ Department of Electrical Technology, Universiti Kuala Lumpur British Malaysian Institute, 50250 Gombak, Selangor, Malaysia. 
commercial vehicles, several policies have been brought by various governments $[1,5]$.

EVs have been enhanced significantly to allow for a long driving range using novel battery technologies and fast-charging stations. The growth of the EV market has led to the significant issues of coming up with novel and innovative ideas to charge them [6-8]. Three significant barriers of EVs are high cost and cycle life of batteries, a complication of chargers, and the lack of charging infrastructures [9]. The chargers are an integral part of EV gridto-vehicle (G2V) drivetrain efficiency. The G2V efficiency for EVs should be close to $45-50 \%$. In order to improve the G2V energy efficiency, a high efficiency, high reliability, high power density, and cost-effective charger design are mandatory [5]. The battery chargers can introduce deleterious harmonic effects on electric utility distribution systems which is another drawback. The introduction of harmonics in the input line current causes low power factor of the fast-charging stations, thus drawing more current from utility, increasing line losses, and reducing the life of the distribution transformers [10].

Based on the power ratings, the chargers are classified as Level 1, Level 2, and Level 3. Level 1 and Level 2 chargers are typically designed for home charging with power less than $2 \mathrm{~kW}$ with a standard voltage of $120 / 230 \mathrm{~V}$ and public charging stations with power $20 \mathrm{~kW}$ with a standard voltage of $120 / 230 \mathrm{~V}$, respectively [11]. The EV charging plug and the adapter for both Level 1 and Level 2 chargers typically comply with the SAE J1772 standard [12]. Level 3 chargers are typically designed for a fast charging using DC with the power rating around $100 \mathrm{~kW}$ with a charging time of less than $30 \mathrm{~min}$. Level 3 chargers are used in commercial charging stations. They are normally connected directly to the medium-voltage three-phase systems. The DC fast-charging station's standards are presented in [13].

Further information for all the levels of charging is provided in Table 1. As a test case, the Nissan Leaf 24 kWh Li-ion battery pack is considered [14].

The review of available Level 3/DC fast-charging techniques is the cornerstone of this paper. The advantages and limitations are also highlighted for better clarity.

Generally, DC fast-charging stations for EVs are designed to supply about $50 \mathrm{~kW}$ of power [15]. The established trend is to place these chargers off-board as these

Table 1 Standard EV charging levels (SAE J1772)

\begin{tabular}{lllll}
\hline Level & Voltage (Vac) & Phase & Power $(\mathrm{kW})$ & Time $(\mathrm{h})$ \\
\hline Level 1 & 120 & One phase & 1.4 & 17 \\
Level 2 & 240 & $\begin{array}{c}\text { One phase and } \\
\text { split phase }\end{array}$ & 4 & 6 \\
Level 3 & $208 / 415$ & $\begin{array}{c}\text { Three phases } \\
\text { The }\end{array}$ & $>20$ & 0.5 \\
\hline
\end{tabular}

stations are bulky. The general block diagram of a DC fastcharging station is shown in Fig. 1, and the charger is connected to a common AC link.

EV battery chargers can be integrated into an EV as an on-board charger or separated as an off-board charger. The power flows between the grids, and EV batteries can be unidirectional or bidirectional. The unidirectional power flow chargers are used as grid-to-vehicle charger applications, and bidirectional power flow chargers are used as grid-to-vehicle and vehicle-to-grid charger applications [16]. Unidirectional chargers can be controlled to charge the EV battery from the grid [17-19].

As per the previous review papers [20-25], they have reviewed two-level AC-DC converters, conventional boost rectifier, zero-voltage transition (ZVT) converters, zero-current transition (ZCT) converters, ZVT-ZCT converters, interleaved boost PFC converters, bridgeless boost PFC converters, and bridgeless interleaved boost PFC converters for the EV charging stations based on the efficiency, power factor, and input current THD and this paper reviews the practical viability of the energy-efficient converters based on the efficiency, power factor, power density, input current THD, and simulation analysis of Vienna rectifier for $\mathrm{EV}$ charging stations is carried out.

This paper presents a review of the recent batterycharging infrastructure for EVs in terms of converter topologies and power control strategies. From the analysis, the suitable converter has selected and simulated with a suitable controller based on the requirement of $D C$ fast charger. In addition, three topologies of Vienna rectifier have been simulated. Based on the results of input current harmonics, output voltage, output current, and efficiency of three topologies of Vienna rectifier are analysed, and the graphs are plotted.

\section{DC fast-charging converter topologies}

There are several numbers of converter topologies available for the rapid charging of batteries or ultra-capacitors. Some feasible options are highlighted in this paper. They are:

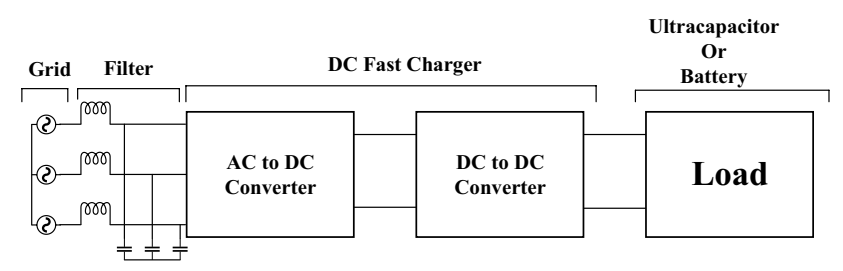

Fig. 1 General block diagram of DC fast-charging station 


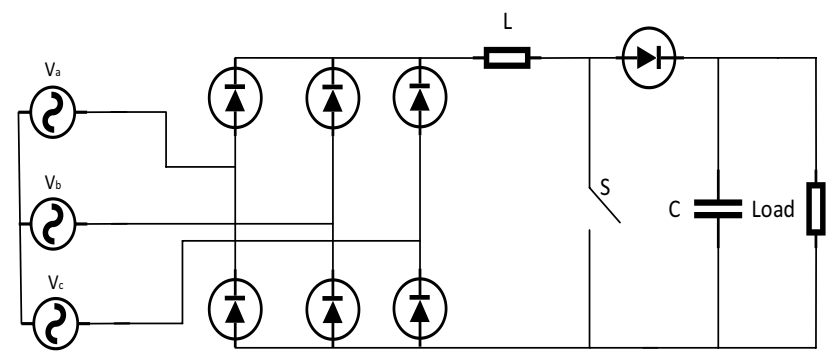

Fig. 2 Unidirectional boost converter [26]

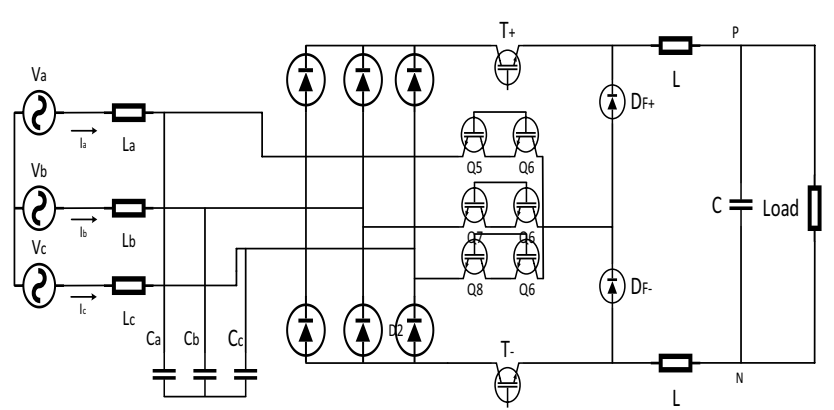

Fig. 3 SWISS rectifier [27]

\subsection{Unidirectional boost converter}

The unidirectional boost converter is shown in Fig. 2, and these converters are employed where the output voltage has to be boosted up for loads which require higher voltage [26].

The primary goal of using a boost converter instead of the conventional diode bridge rectifier is to improve power factor, to reduce the harmonics at the end, and to have a controlled DC voltage at the output if unwanted perturbations occur at the $\mathrm{AC}$ end.

\subsection{SWISS rectifier}

The SWISS rectifier is shown in Fig. 3, and these rectifiers are employed where the efficiency has to be increased based on the application requirements [27].

The significant achievement in using the SWISS rectifier is to provide better efficiency compared to the conventional rectifiers. Compared to boost-type converter, buck-type system provides a wide output voltage control range, while maintaining PFC capability in the input, enables direct start-up, and allows for dynamic current limitations at the output.

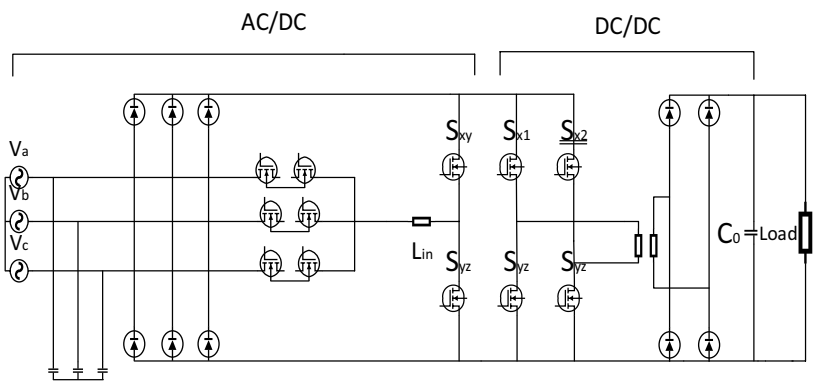

Fig. 4 Matrix converter [28]

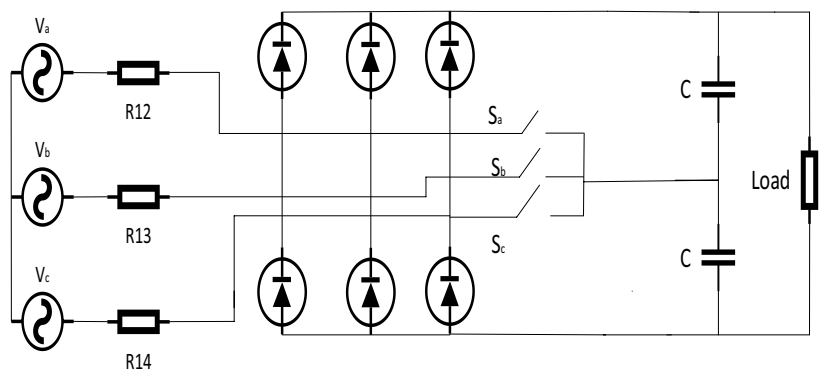

Fig. 5 Vienna rectifier [26]

\subsection{Matrix converter}

The matrix converter is shown in Fig. 4, and these rectifiers are used for the regenerative operation of charging stations where it has to be used for the vehicle-to-grid applications with high efficiency [28].

Matrix converter is a forced commutated converter that uses an array of controlled bidirectional switches which allows high-frequency operations. This type of converter does not require DC-link circuit and any large energy storage element. It can improve the power factor and reduce the harmonics in the line current at the end.

\subsection{Vienna Rectifier}

Another famous power converter for power quality improvement is the Vienna rectifier, as shown in Fig. 5. This is the popular choice when the aim is to achieve a high power factor and to attain lower harmonics distortion. The switching losses in Vienna rectifier are low because of low voltage stress in the switches $[29,30]$. This converter consists of only one active switch per phase which makes the Vienna rectifier easier to control and makes it more dependable. This converter is basically a PWM converter [31], and the boost inductor at the input plays the role in ascertaining power factor correction. Basically, the stored energy acquired by the inductor when the switch is OFF is transmitted to the load through the diodes whenever the 
switch is ON. The advantage of employing this topology includes the absence of a neutral point connection [32].

\section{Performance comparison of energy-efficient converters}

\subsection{Comparative Analysis of Charging Converter Topologies}

Some of the features of the converter topologies are discussed and are highlighted in Table 2. From the detailed review of the few converter topologies, it can be concluded that the use of the Vienna rectifier for the implementation of the charging station is appropriate, due to the following reasons:

- It has less number of switches per phase.

- Harmonic contents are compensated.

- Good efficiency when compared to the PWM rectifier, SWISS rectifier, and matrix converter.

- Higher power factor, around 0.99, compared to the PWM rectifier, SWISS rectifier, and matrix converter.

The features of converter topologies are highlighted in Table 2. From the analysis, both the SWISS rectifier and Vienna rectifier have high efficiency with less than $5 \%$ THD. However, the Vienna rectifier is the most optimal converter topology for the charging stations as it has the advantages of high power density $\left(12 \mathrm{~kW} / \mathrm{dm}^{3}\right)[37,38]$ compared to the SWISS rectifier $\left(4 \mathrm{~kW} / \mathrm{dm}^{3}\right)$ [32]. It is evident that the Vienna rectifier has been selected for designing DC fast charger as it has the advantage of high power density. The comparison of energy-efficient converters based on practical applications is given in Table 3. It can be seen from Table 3 that the Vienna rectifier can be used for EV charging system as it features high efficiency, high power density, unity power factor, and low total harmonic distortion, and the size of the system is small compared to other converters.

\section{Control strategies of energy-efficient converters}

Various control algorithms have been developed to improvise the power factor due to the harmonic distortions, different types of power controllers such as hysteresis current controller [47], SPWM controller [48], a direct power control (DPC) $[49,50]$. The direct power control requires high inductance and sample frequency. The hysteresis controller is most commonly used but with more switching loss due to variable switching frequency, and in [51], it is originally used for thermostatically controlled loads [52] and is used for plug-in electric vehicle (PEV) charging to actively control the consumption of a higher number of chargers. In addition, several studies have established that model predictive control (MPC) reduces the harmonics in the line current and a smaller mean absolute current reference tracking error as compared to other controllers. In [53], the author presented a predictive current control method for reducing the total harmonic distortion (THD) by using a switching frequency of $8 \mathrm{kHz}$ with a voltage source inverter. In [54], the researcher applied the model predictive control algorithm for a four-leg converter to observe the reduction in THD and switching frequency at low values of the filter parameters. In [55], a comparative study between a finite-control-set MPC (FCS-MPC) and synchronous proportional-integral (PI) controller with space vector modulation (PI-SVM) has been established; it was observed that the FCS-MPC is able to generate waveforms with fewer lower-order harmonics than the PI-SVM. The MPC method is able to operate with different voltage/frequency values while maintaining a lower THD value [56-58]. However, MPC requires complex implementation as compared to linear controllers. Meanwhile, in the single-phase on-board bidirectional charger proposed by

Table 2 Performance comparison of DC fast-charging converter topologies [33]

\begin{tabular}{|c|c|c|c|c|c|c|}
\hline Converter topology & Reference & Mode of operation & $\begin{array}{l}\text { Phase cur- } \\
\text { rent THD (\%) }\end{array}$ & Distinct feature & Efficiency (\%) & $\begin{array}{l}\text { Power den- } \\
\text { sity }(k W / \\
{\left.d m^{3}\right)}^{3}\end{array}$ \\
\hline Unidirectional boost converter & {$[34]$} & Boost & $\sim 30$ & $\begin{array}{l}\text { Simple design } \\
\text { Fast switching }\end{array}$ & 63.5 & 2.6 \\
\hline SWISS rectifier & {$[32,35]$} & Buck & $<5$ & Efficiency is higher & 99.3 & 4 \\
\hline Matrix converter & {$[28]$} & Buck-boost & $\sim 20$ & Bidirectional converter & 98 & 4 \\
\hline Vienna rectifier & [36-38] & Boost & $<5$ & $\begin{array}{l}\text { High power density } \\
\text { High power factor } \\
\text { No requirement of neu- } \\
\text { tral connection }\end{array}$ & 99 & 12 \\
\hline
\end{tabular}




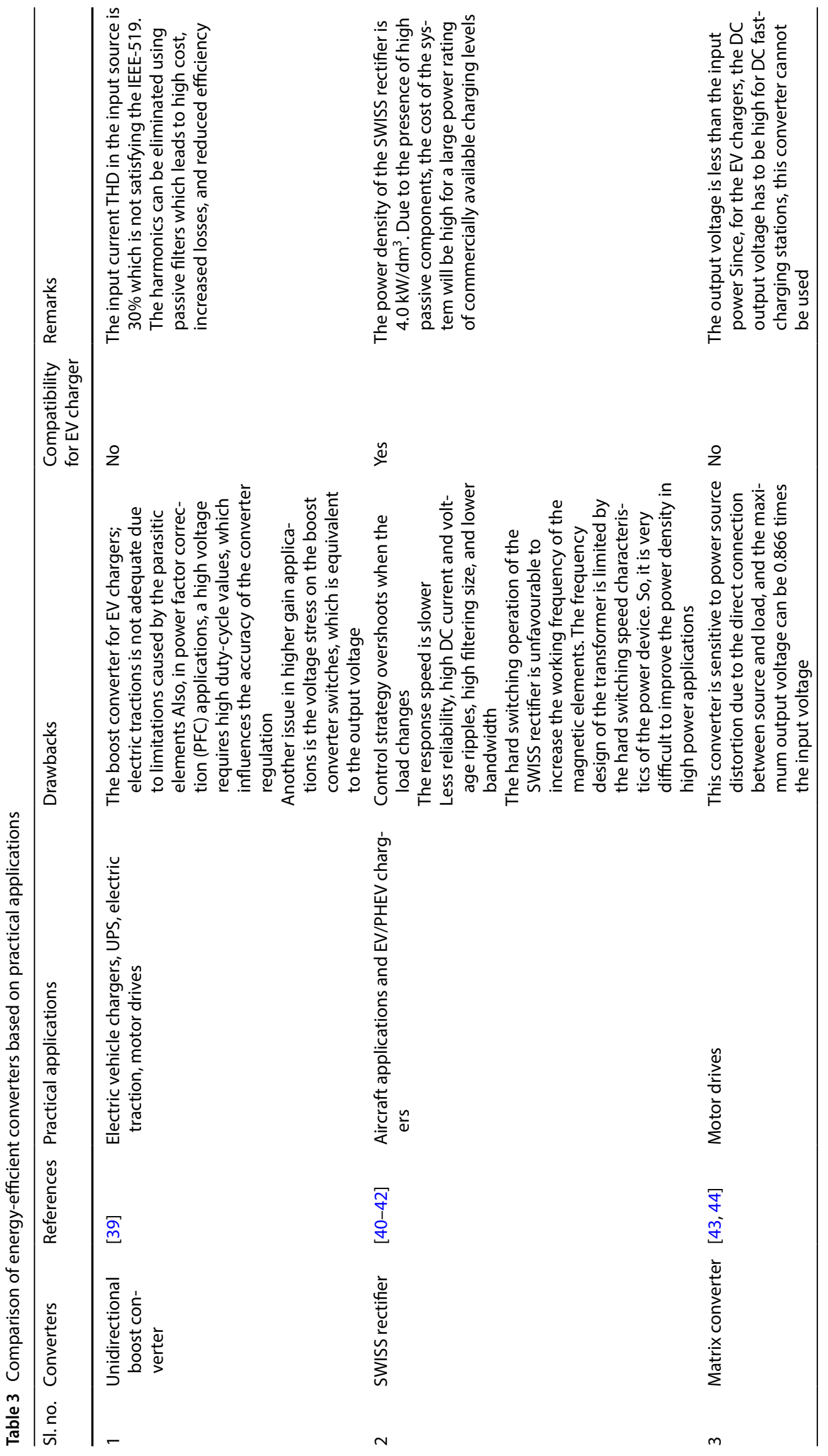




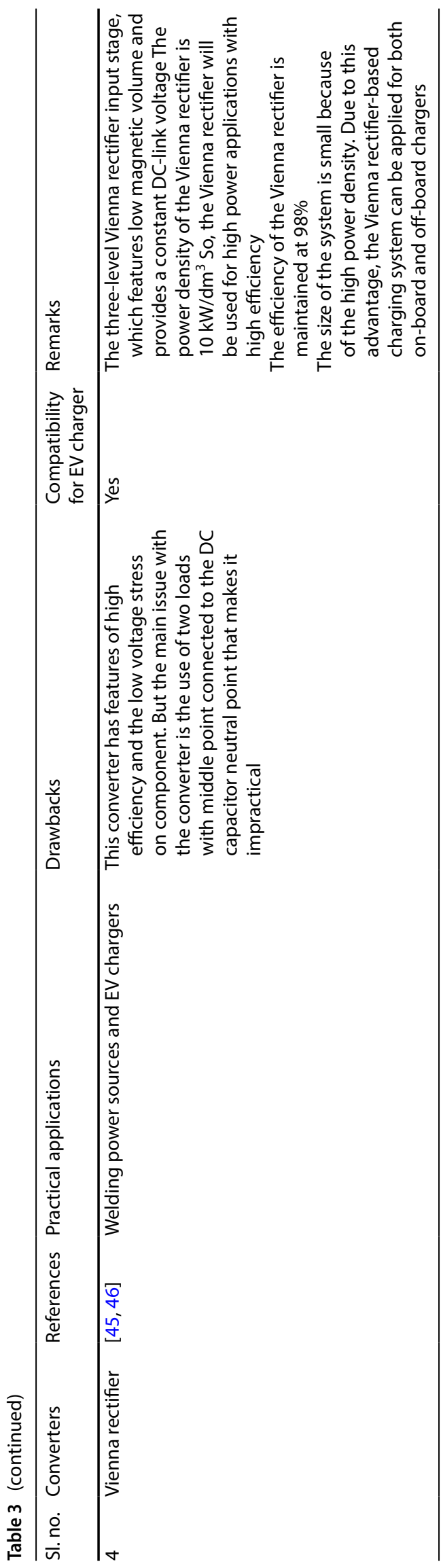

[17], PI controllers were employed in AC/DC converters and DC/DC converters which provide constant voltage and constant current charging, as well as reactive power compensation. However, the THD of the line current was high.

In this paper, the PFC consisting of PI controller has been analysed for improving the power quality such as harmonics and power factor. The PFC with the PI controller is shown in Fig. 6. Other control strategies such as adaptive control, fuzzy logic control, sliding mode control, predictive control, or neural network control can be applied to improve the performance of the charging stations.

The PFC controller consists of three PI controllers which can regulate the $D C$ output voltage based on the reference voltage. Small overshoot, good damping of oscillations, and fast response are the three fundamental goals of the designer for the synthesis of the involved PI controller in a control loop. This PFC controller has two outer voltage loops and one inner current loop. The evaluation of PI controller parameters is one of the key issues in the design of a cascaded structure where the inner loop is designed to achieve fast response and outer loops are designed to achieve optimum regulation and stability [59].

\section{Topologies of Vienna rectifier for charging stations}

\subsection{Topology of the Vienna rectifiers}

A single-phase Vienna rectifier topology employed in this study is shown in Fig. 7. The input filter of these topologies is composed of an inductor, $L$. The resistor $R$, means the resistive components in the inductor. The converter stated in this paper is similar to that of a single-phase T-type inverter, with the outer switches of the inverter having been replaced by the diodes in the rectifier. The rectifier topologies include the inner switch, which only operates when the top capacitor is charging. The circuit with fewer switches leads to less THD in the line current due to the frequency of switching, which leads to an improvement in the power factor at the source side. The key characteristics of this converter known as split capacitor consists of two capacitors being placed at the output side, that reduces the voltage stress on to the power semiconductor switches. The voltage across each capacitor is $+\frac{V_{0}}{2}$ and $-\frac{V_{0}}{2}$ which detects the output voltage of the circuit. So, Vienna rectifier has three voltages such as $+\frac{V_{0}}{2}, 0$, and $-\frac{v_{0}}{2}$. The capacitors at the output side are to reduce the voltage stress on the switches and also used to prevent the rapid voltage change at the output side. So, the cost of the converter can be reduced. The ratings used in this topological analysis are shown in Table 4.

SN Applied Sciences 
Fig. 6 PFC with PI controller for EV applications [17]
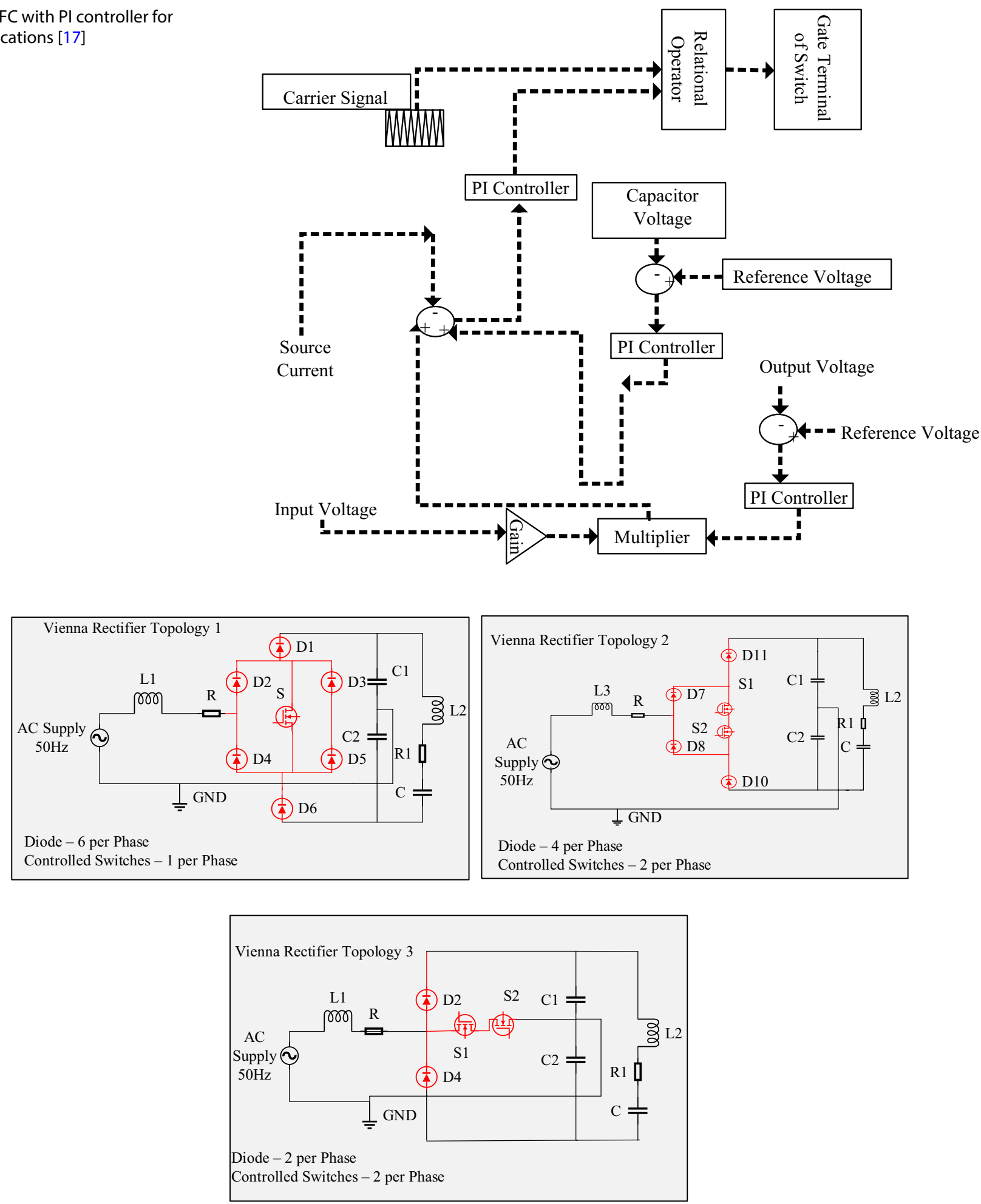

Fig. 7 Different topologies of Vienna rectifier 

analysis of $95 \%$ efficiency
Table 4 Rating of load for the

\begin{tabular}{ll}
\hline Parameter & Rating \\
\hline Input power & $10.5 \mathrm{~kW}$ \\
Input frequency & $50 \mathrm{~Hz}$ \\
Output power & $10 \mathrm{~kW}$ \\
\hline
\end{tabular}

\subsection{Mathematical Formulations for the Analysis}

\subsubsection{Topology 1}

In this topology, the power factor correction controller is used to control the output voltage to a constant value and to make the input current sinusoidal. However, this topology has only one semiconducting switch and six diodes which reduce the efficiency of the system. Due to this connection, one of the most outstanding merit can be achieved which is low voltage stress on each component that will reduce half of the total DC bus voltage at each interval. By using analytical approximations, the average and the RMS current ratings of the semiconductor have been calculated [60]. By using the inductor present in the input side, these types of converter can increase the DC output voltage and improve the power quality in the input side as well.

The diode average $\left(I_{D_{2, a v g}}\right)$ and RMS current $\left(I_{D_{2, a v g}}\right)$ are calculated using Eqs. (1) and (2).

$I_{D_{2, \text { avg }}}=\frac{1}{\pi} \hat{I}_{N}$

$I_{D_{2, \text { RMS }}}=\frac{1}{2} \hat{l}_{N}$

The diode $\mathrm{D}_{3}$ average $\left(I_{\mathrm{D}_{3, \text { avg }}}\right)$ and RMS current $\left(I_{\mathrm{D}_{3, \mathrm{RMS}}}\right)$ are calculated as in Eqs. (3) and (4).

$$
\begin{aligned}
& I_{D_{3, \text { avg }}}=\left(\frac{1}{\pi}-\frac{1}{2 \sqrt{3} M}\right) \hat{I}_{N} \\
& I_{\mathrm{D}_{3, \text { RMS }}}=\sqrt{\frac{1}{4}-\frac{4}{3 \sqrt{3} M} \frac{1}{M}} \hat{I}_{N}
\end{aligned}
$$

The diode $\mathrm{D}_{3}$ average $\left(I_{\mathrm{D}_{1, \text { avg }}}\right)$ and RMS current $\left(I_{\mathrm{D}_{1, \mathrm{RMS}}}\right)$ are calculated as in Eqs. (5) and (6).

$$
\begin{aligned}
& I_{\mathrm{D}_{1, \text { avg }}}=\frac{1}{2 \sqrt{3} M} \hat{l}_{N} \\
& I_{\mathrm{D}_{1, \text { RMS }}}=\sqrt{\frac{4}{3 \sqrt{3} \pi} \frac{1}{M}} \hat{l}_{N}
\end{aligned}
$$

The MOSFET average $\left(I_{\mathrm{S}_{\mathrm{avg}}}\right)$ and RMS current $\left(I_{\mathrm{S}_{\mathrm{RMS}}}\right)$ are calculated by using Eqs. (7) and (8).

$I_{S_{\text {avg }}}=\left(\frac{2}{\pi}-\frac{1}{\sqrt{3} M}\right) \hat{I}_{N}$

$I_{\mathrm{SMS}}=\sqrt{\frac{1}{2}-\frac{8}{3 \sqrt{3} \pi} \frac{1}{M}} \hat{I}_{N}$

The capacitor ripple current $\left(\mathrm{I}_{\mathrm{C}_{\text {out,RMS }}}\right)$ is calculated using Eq. (9).

$I_{\mathrm{C}_{\text {out }, \mathrm{MMS}}}=\sqrt{\frac{10 \sqrt{3} M}{8 \pi}-\frac{9 M^{2}}{16} \hat{l}_{N}}$

where $\hat{l}_{N}$ is the peak line current, $M=\frac{U_{0}}{\sqrt{3} \hat{U}_{N}}$ is the transformation ratio, $U_{o}$ is the DC output voltage, and $\hat{U}_{N}$ is the peak phase voltage.

\subsubsection{Topology 2}

In Topology 2, the freewheeling diode currents $I_{D 2}$ and $I_{D 4}$ and the capacitor ripple current $\mathrm{I}_{\mathrm{C}}$ remain the same as the Topology 1 , and the MOSFET current is divided into two MOSFETs. To reduce the voltage stress on the switches, two capacitors are connected in parallel to minimize the losses in the switches [61].

The diode average $\left(I_{\mathrm{D}_{7, \text { av }}}\right)$ and RMS current $\left(I_{\mathrm{D}_{7, \mathrm{RMS}}}\right)$ are calculated using Eqs. (10) and (11).

$I_{D_{7, \text { avg }}}=\frac{1}{2 \sqrt{3} M} \hat{I}_{N}$

$I_{\mathrm{D}_{7, \mathrm{RMS}}}=\sqrt{\frac{4}{3 \sqrt{3} \pi} \frac{1}{M}} \hat{I}_{N}$

The diode $\mathrm{D}_{10}$ average $\left(I_{\mathrm{D}_{10, \mathrm{avg}}}\right)$ and RMS current $\left(I_{\mathrm{D}_{10, \mathrm{RMS}}}\right)$ are in Eqs. (12) and (13).

$I_{\mathrm{D}_{10, \mathrm{avg}}}=\frac{1}{\pi} \hat{l}_{N}$

$I_{D_{10, R M S}}=\frac{1}{2} \hat{l}_{N}$

The MOSFET average $\left(I_{S_{\text {avg }}}\right)$ and RMS current $\left(I_{S_{\text {RMS }}}\right)$ are calculated by using Eqs. (14) and (15).

$I_{\mathrm{S}_{\mathrm{avg}}}=\left(\frac{1}{\pi}-\frac{1}{2 \sqrt{3} M}\right) \hat{I}_{N}$ 
$I_{\mathrm{S}_{\mathrm{RMS}}}=\sqrt{\frac{1}{4}-\frac{4}{3 \sqrt{3} \pi} \frac{1}{M}} \hat{l}_{N}$

The capacitor ripple current $\left(I_{C_{\text {out,RMs }}}\right)$ is calculated using Eq. (16).

$I_{C_{\text {out }, \text { MM }}}=\sqrt{\frac{10 \sqrt{3 M}}{8 \pi}-\frac{9 M^{2}}{16} \hat{l}_{N}}$

\subsubsection{Topology 3}

The Topology 1 and Topology 2 have no redundancy states to balance the voltage of the capacitor continuously. This is the main drawback of above-mentioned topologies which leads to high voltage ripple at DC output. In Topology 2 , the voltage ripple is minimized by balancing the voltage using two switches connected in anti-parallel to the neutral. In Topology 3, the freewheeling diode current remains the same as others. As the switch is made up of two MOSFETs, it is different from the Topology 1 which reduces the voltage stress on the switches and it has only two diodes in the circuit which reduces the losses in the diodes. Due to this design, the losses from the diodes have been reduced, and the rating of the switch has been reduced; it leads to a reduction in the cost of the device and increase in efficiency as well.

The diode average $\left(I_{D_{2, a v g}}\right)$ and RMS current $\left(I_{D_{2, R M S}}\right)$ are calculated using Eqs. (17) and (18).

$I_{D_{2, \text { avg }}}=\frac{1}{2 \sqrt{3} \pi} \hat{l}_{N}$

$I_{\mathrm{D}_{2, \mathrm{RMS}}}=\sqrt{\frac{2}{3}-\frac{8}{3 \sqrt{3}} \frac{1}{M}} \hat{l}_{N}$

The MOSFET average $\left(I_{S_{\text {avg }}}\right)$ and RMS current $\left(I_{S_{\text {RMS }}}\right)$ are calculated by using Eqs. (19) and (20).

$$
\begin{aligned}
& I_{\mathrm{S}_{\text {avg }}}=\left(\frac{2}{\pi}-\frac{1}{\sqrt{3} M}\right) \hat{I}_{N} \\
& I_{\mathrm{S}_{\mathrm{RMS}}}=\sqrt{\frac{1}{2}-\frac{8}{3 \sqrt{3} \pi} \frac{1}{M}} \hat{I}_{N}
\end{aligned}
$$

In this topology, the switches are connected in the back-back connection of MOSFETs. During the positive half cycle, MOSFET $S_{1}$ and diode of $S_{2}$ conduct, and in negative half cycle MOSFET $S_{2}$ and diode of $S_{1}$ conduct.
Combined diode and MOSFET average $\left(I_{T_{\text {avg }}}\right)$ and RMS current $\left(I_{T_{\text {RMS }}}\right)$ are calculated by using Eq. (21)-Eq. (22).

$I_{T_{\text {avg }}}=\left(\frac{1}{\pi}-\frac{1}{2 \sqrt{3} M}\right) \hat{I}_{N}$

$I_{\mathrm{T}_{\mathrm{RMS}}}=\sqrt{\frac{1}{4}-\frac{4}{3 \sqrt{3} \pi} \frac{1}{M}} \hat{I}_{N}$

The capacitor ripple current $\left(I_{C_{\text {out RnS }}}\right)$ is calculated using Eq. (23).

$I_{C_{\text {out RMS }}}=\sqrt{\frac{10 \sqrt{3} M}{8 \pi}-\frac{9 M^{2}}{16} \hat{I}_{N}}$

\subsubsection{Efficiency Computations}

The conduction loss $\left(C_{L}\right)$ for the diodes in the circuit is calculated using Eq. (24).

$C_{\mathrm{L}}=l_{\text {avg }} \times V_{\mathrm{f}}$

where $V_{f}$ is the forward voltage drop of the diode at the particular $l_{\text {avg }}$ as provided by the diode data sheet $\left(V_{\mathrm{f}}\right.$ normally ranges from 0.6 to $1.1 \mathrm{~V}$ ). The switching loss $\left(S_{L}\right)$ for the devices is given in Eq. (25).

$S_{\mathrm{L}}=\frac{1}{2} C V^{2} f$

where $C$ is the capacitance of the junction, $V$ is the blocking voltage, and $f$ is the switching frequency.

The conduction loss in the MOSFETs $\left(C_{L 1}\right)$ is calculated using Eq. (26).

$C_{\mathrm{L} 1}=l_{\mathrm{rms}}^{2} \times R_{\mathrm{DS}}$

where $R_{\mathrm{DS}}$ is the source-to-drain resistance at the operating temperature.

The switching loss during turn on and turn off is calculated using Eqs. (27) and (28).

$S_{\text {on }}=\frac{1}{2} V I_{\text {rms }} t_{r} f_{s w}$

$S_{\text {off }}=\frac{1}{2} V I_{\text {rms }} t_{f} f_{s w}$

where $f_{\mathrm{sw}}$ is the switching frequency, $t_{\mathrm{r}}$ is the rise time, and $t_{\mathrm{f}}$ is the fall time. 
Table 5 Comparison of components in terms of number of devices

\begin{tabular}{llll}
\hline Parameters & Topology 1 & Topology 2 & Topology 3 \\
\hline $\begin{array}{l}\text { No. of low-frequency } \\
\text { diodes }\end{array}$ & 12 & 6 & 0 \\
$\begin{array}{l}\text { No. of high-frequency } \\
\text { diodes }\end{array}$ & 6 & 6 & 6 \\
$\begin{array}{l}\text { No. of MOSFET } \\
\text { No. of MOSFET driver }\end{array}$ & 3 & 6 & 6 \\
\hline
\end{tabular}

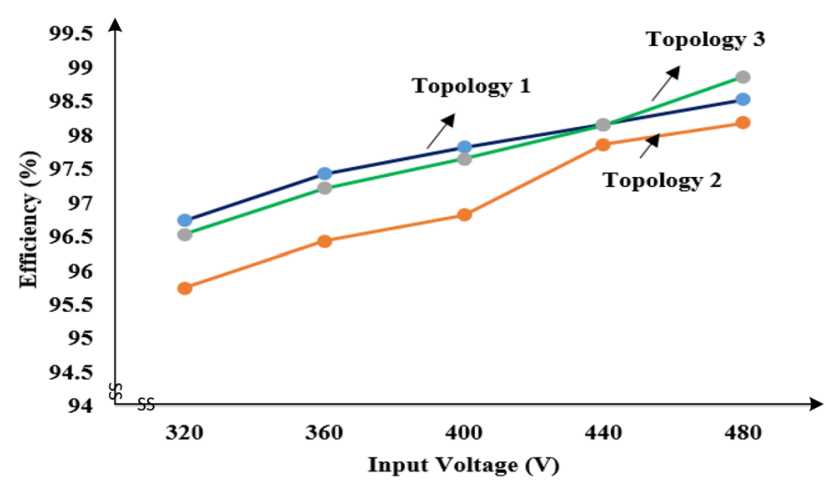

Fig. 8 Efficiency characteristics

\section{Results and analysis}

\subsection{Efficiency analysis}

The number of switches, type, and the number of diodes for different topologies are given in Table 5, and it is observed that the number of components available in Topology 3 is low. The three topologies of the Vienna rectifier at $50 \mathrm{kHz}$ are calculated for the efficiency values and are plotted in Fig. 8.

The Topology 1 has higher efficiency in between the input voltages of $320 \mathrm{~V}$ and $400 \mathrm{~V}$, compared to Topology 2 and Topology 3, which is shown in Fig. 8. Beyond $400 \mathrm{~V}$, due to the more number of switches in Topology 1, the switching losses will increase. So, the efficiency of Topology 3 overtakes the Topology 1, and for a wide range of input voltage, it is more efficient than other topologies.
From Table 4, it is noted that the number of switches in Topology 3 is less compared to the other two topologies. Due to this, the losses in Topology 3 are very less, which leads to more efficiency.

\subsection{Input Current Characteristics}

It is noted that the input current waveform for three topologies is almost sinusoidal. The input current is shown in Fig. 9. In all three topologies, there are slight changes in the harmonics, which leads to minor variations in the sinusoidal waveform of input current. Compared to all three topologies, Topology 3 has the sinusoidal input current which indicates unity power factor at the input power supply.

\subsection{Input Current THD Spectrum}

It is noted that the percentage input current THD for Topology 1 is 4.11 , which is less than $5 \%$, and it is meeting the IEEE standards. Due to the more number of switches in Topology 2, the harmonics on the input current are less compared to Topology 1 which is $6.45 \%$ and it fails to meet the IEEE standards. This leads to more losses in Topology 2, and the efficiency of the circuit has been reduced. The percentage input current THD for Topology 3 is 2.38 , which is less than $5 \%$, and it satisfies the IEEE standards. Among all the three topologies, it is evident from the analysis that the performance of Topology 3 is better compared to Topologies 1 and 2. The percentage input current THD for the three topologies is shown in Fig. 10.

\subsection{Output Voltage of Vienna Rectifier Topologies}

The DC output voltage is almost constant in all the topologies. The output DC voltage for three topologies is shown in Fig. 11.

\subsection{Performance Evaluations of the Vienna Rectifier Topologies}

It can be seen from Table 6 that the Topology 3 is providing better performance in terms of THD value compared to other topologies. The introduction of harmonics is because of the number of diodes and controlled switches present in the converters. Topology 1 has more semiconductor switches compared to Topology 2 and Topology 3 which leads to more losses in Topology 1 , and it reduces 


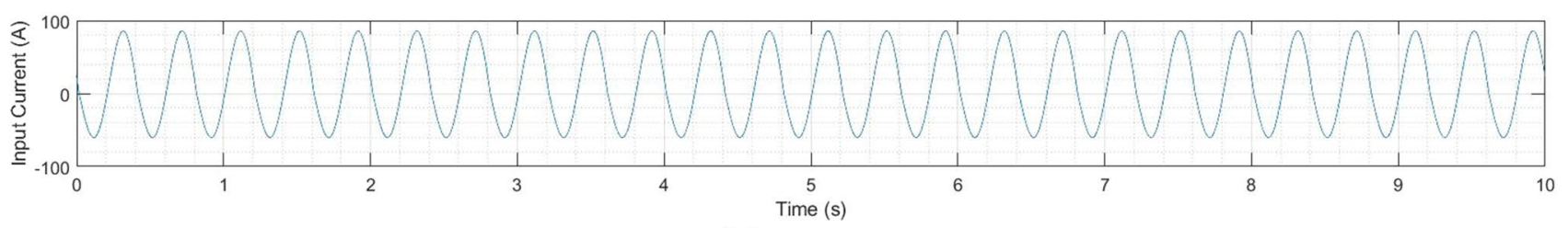

(a) Topology 1

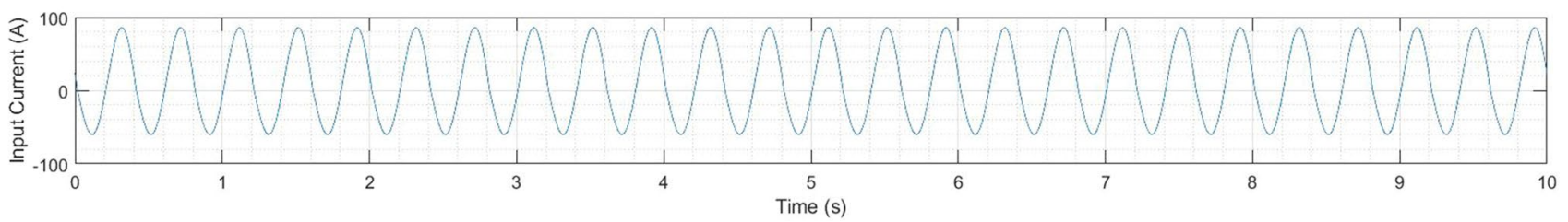

(b) Topology 2

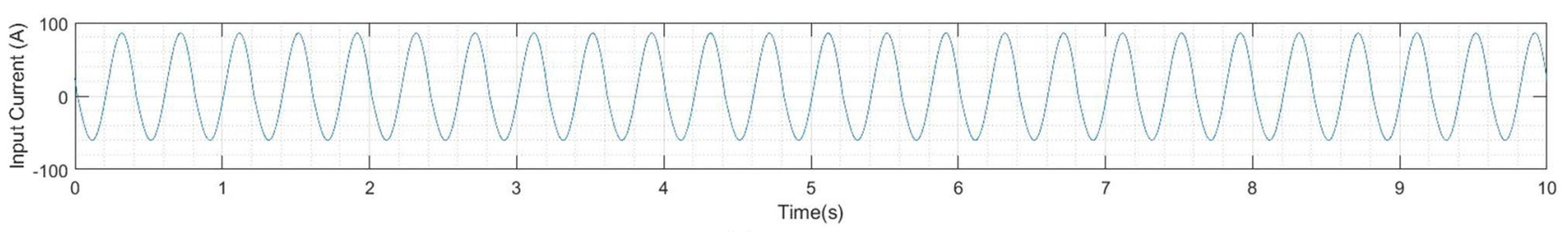

(c) Topology 3

Fig. 9 Input current waveforms of three topologies of Vienna rectifier

the efficiency of the system. Even though Topology 3 has the same number of controlled switches, the number of diodes is less compared to Topology 2. Due to this, the harmonics on the input current in Topology 2 increased to more than $5 \%$ which affects the power quality of the source. In Topology 3, the power factor has been improved to unity with the reduction of THD in the input current. It reduces the losses in the circuit and increases the efficiency of the system.

\section{Conclusion}

This article comprehensively explore different types of energy efficient converter topologies for power factor assessment at the electric vehicle charging stations. It is understood from the literature review, the Vienna rectifier is a preferred choice in the high power applications, due to superior power factor and excellent capability to cancel out current harmonics.

In this paper, three topologies of the Vienna rectifier were compared using the following parameters.
1. Number of active/passive devices.

2. Total loss and efficiency.

3. Input current THD.

4. Power factor.

The losses for the three topologies of the Vienna rectifier have been calculated for the full load by using the formulas at different input voltages. The comparison of different topologies of Vienna rectifier for the efficiency has been made and plotted. From the analysis of three topologies of Vienna rectifier, it is observed that the Topology 3 using a minimum number of semiconductor switches is compared to other topologies. Topologies 1 and 3 are having the closest values of efficiency, and beyond $400 \mathrm{~V}$, Topology 3 operates at higher efficiency at $99 \%$. The performance of three topologies is simulated and analysed in terms of a number of active/passive devices, total loss and efficiency, power factor, and THD. It can be concluded that the Topology 3 is the most suitable converter for the electric vehicle charging stations and it is benchmarked for less complexity, high efficiency, high power density design, less input current THD, and improved power factor. 
Fig. 10 THD for three topologies of Vienna rectifier

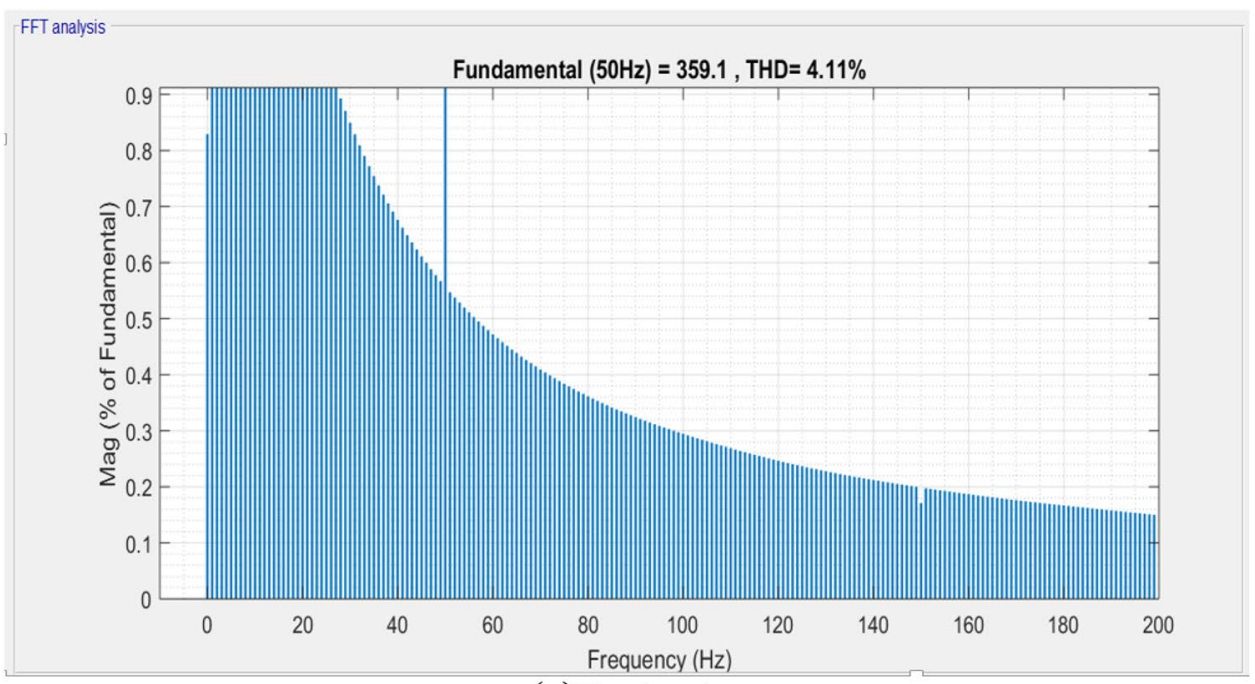

(a) Topology 1

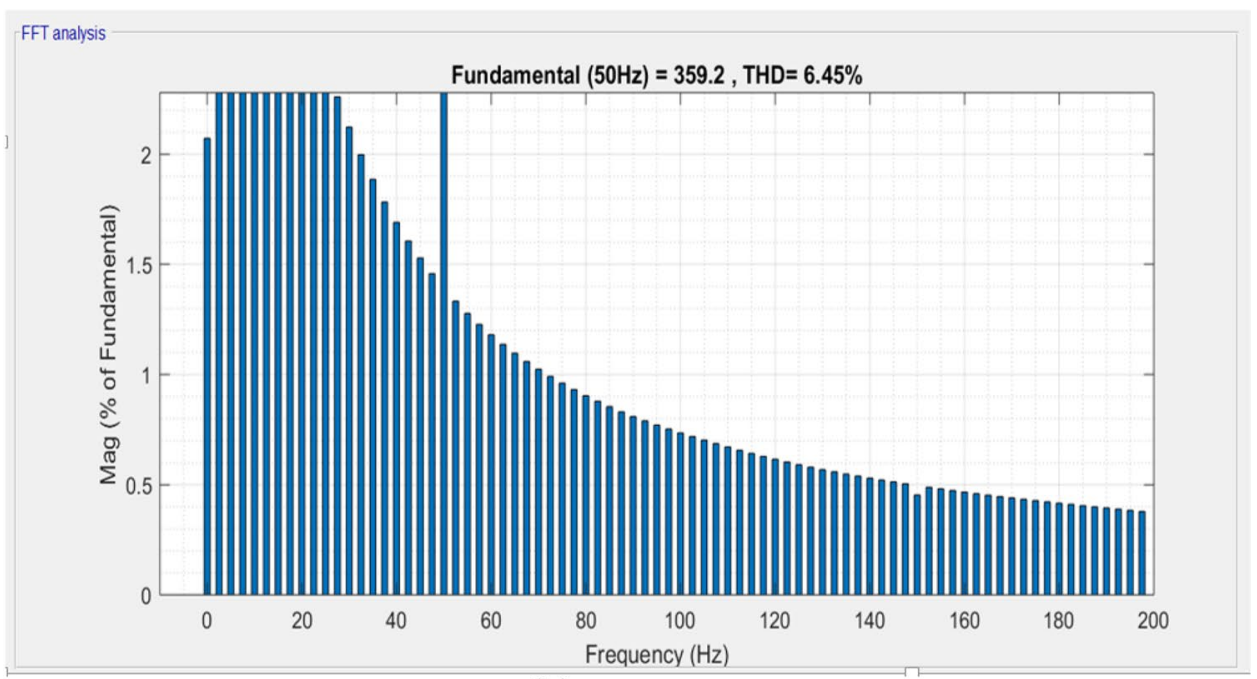

(b) Topology 2

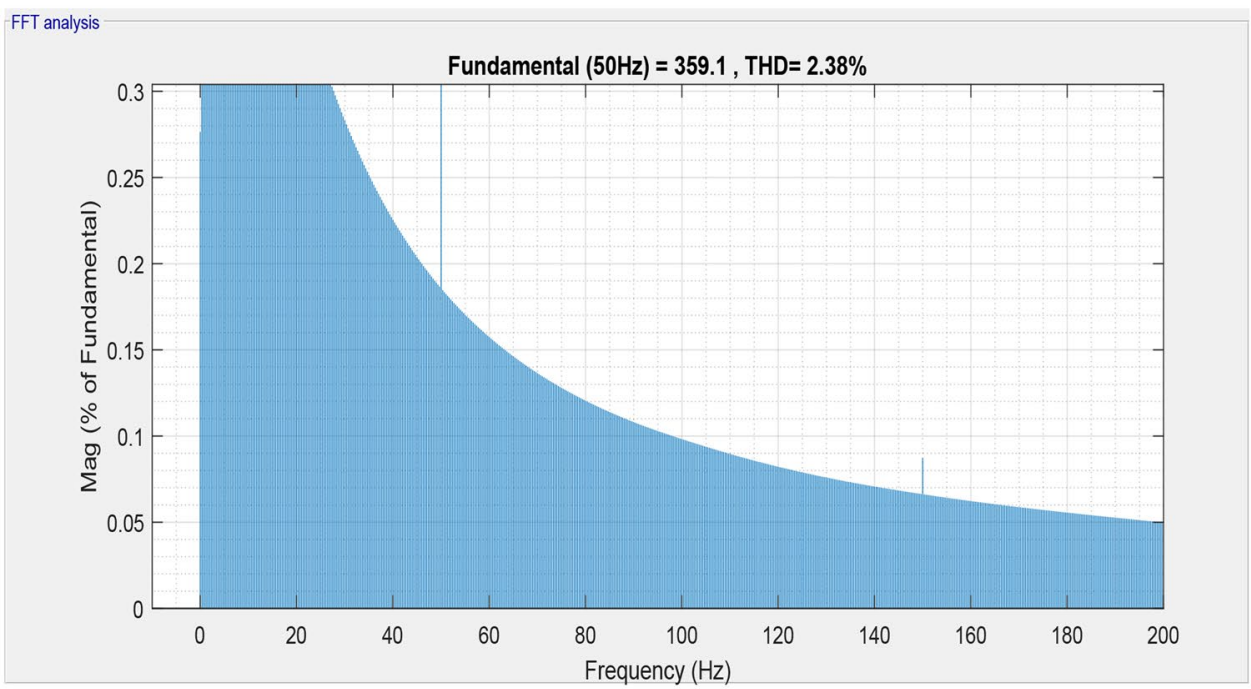

(c) Topology 3 


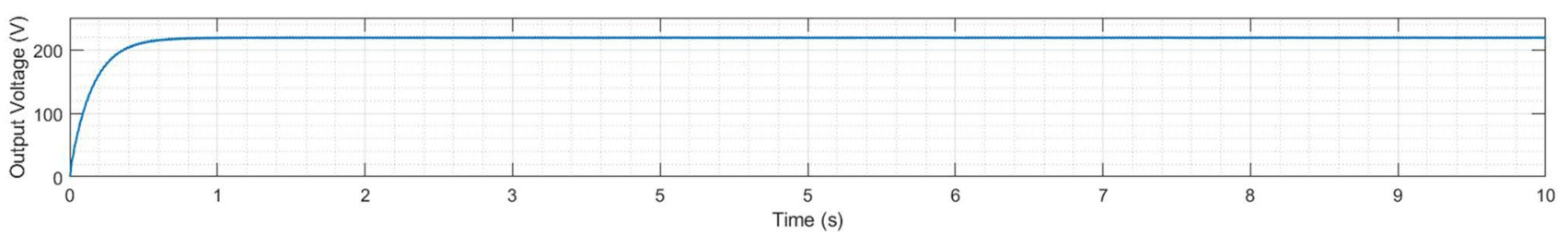

(a) Topology 1

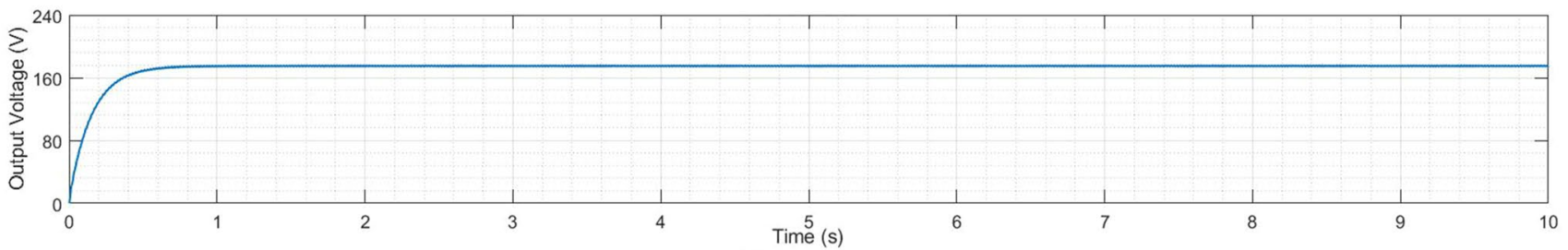

(b) Topology 2

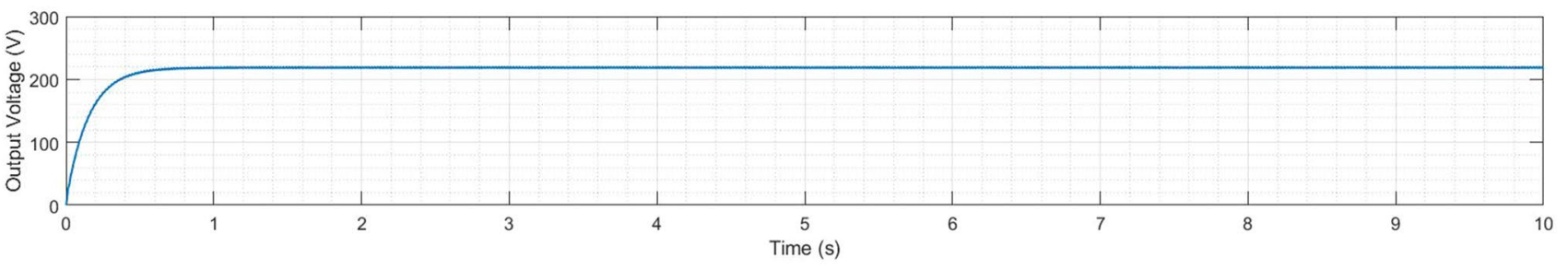

(c) Topology 3

Fig. 11 Output DC voltage of three topologies of Vienna rectifier

Table 6 Comparison of topologies in terms of THD and power factor

\begin{tabular}{lllll}
\hline Parameters & $\begin{array}{l}\text { No. of } \\
\text { controlled } \\
\text { switches per } \\
\text { phase }\end{array}$ & $\begin{array}{l}\text { No. of } \\
\text { diodes per } \\
\text { phase }\end{array}$ & $\begin{array}{l}\text { Input } \\
\text { current } \\
\text { THD }\end{array}$ & Power factor \\
\hline Topology 1 & 1 & 6 & 4.11 & 0.91 \\
Topology 2 & 2 & 4 & 6.45 & 0.93 \\
Topology 3 & 2 & 2 & 2.38 & 0.96 \\
\hline
\end{tabular}

Acknowledgements This work is supported by Taylor's University under its TAYLOR'S RESEARCH SCHOLARSHIP Programme through grant TUFR/2017/001/01.

\section{Compliance with ethical standards}

Conflict of interest The authors declare that they have no conflict of interest.

\section{References}

1. Energy Agency, I. Global EV Outlook 2019 to electric mobility. Available online: www.iea.org/publications/reports/globalevou tlook2019/
2. Aggeler D, Canales F, Zelaya-De La Parra H, Coccia A, Butcher $\mathrm{N}$, Apeldoorn O (2010) Ultra-fast DC-charge infrastructures for EV-mobility and future smart grids. In: IEEE PES innovative smart grid technology conference Europe. ISGT Europe, pp 1-8

3. Lee YJ, Khaligh A, Emadi A (2009) Advanced integrated bidirectional AC/DC converter for plug-in hybrid electric vehicles. IEEE Trans Veh Technol 58:3970-3980

4. Emadi A, Williamson SS, Khaligh A (2006) Power electronics intensive solutions for advanced vehicular power systems. IEEE Trans Power Electron 21:567-577

5. Gautam DS, Musavi F, Edington M, Eberle W, Dunford WG (2012) An automotive onboard 3.3-kW battery charger for PHEV application. IEEE Trans Veh Technol 61:3466-3474

6. Kesler M, Kisacikoglu MC, Tolbert LM (2014) Vehicle-to-grid reactive power operation using plug-in electric vehicle bidirectional offboard charger. IEEE Trans Ind Electron 61:6778-6784

7. Xu NZ, Chung CY (2016) Reliability evaluation of distribution systems including vehicle-to-home and vehicle-to-grid. IEEE Trans Power Syst 31:759-768

8. Yilmaz M, Krein PT (2013) Review of the impact of vehicle-togrid technologies on distribution systems and utility interfaces. IEEE Trans Power Electron 28:5673-5689

9. Chan CC, Chau KT (1997) An overview of power electronics in electric vehicles. IEEE Trans Ind Electron 44:3-13

10. Clement K, Haesen E, Driesen J (2008) The impact of charging plug-in hybrid electric vehicles on the distribution grid. In: Proceeding of 2008-4th IEEE BeNeLux young research symposium electric power engineering, vol 25, pp 1-6

11. Chukwu UC, Mahajan SM (2014) V2G parking lot with PV rooftop for capacity enhancement of a distribution system. IEEE Trans Sustain Energy 5:119-127 
12. Yilmaz M, Krein PT (2012) Overview introduction charger power levels unidirectional and bidirectional chargers integrated chargers conductive and inductive charging conclusion. In: 2012 IEEE international electric vehicle conference, pp 1-33

13. Yilmaz M, Krein PT (2013) Review of battery charger topologies, charging power levels, and infrastructure for plug-in electric and hybrid vehicles. IEEE Trans Power Electron 28:2151-2169

14. Hayes JG, Davis K (2014) Simplified electric vehicle powertrain model for range and energy consumption based on EPA coastdown parameters and test validation by argonne national lab data on the nissan leaf. In: IEEE 2014 transportation electrification conference and expo (ITEC), Dearborn, MI, 2014, pp 1-6

15. Wang S, Crosier R, Chu Y (2012) Investigating the power architectures and circuit topologies for megawatt superfast electric vehicle charging stations with enhanced grid support functionality. In: 2012 IEEE international electric vehicle conference, pp $1-8$

16. Schrittwieser L, Leibl M, Haider M, Thony F, Kolar JW, Soeiro TB (2018) 99.3\% efficient three-phase buck-type all-SiC SWISS rectifier for DC distribution systems. IEEE Trans Power Electron 34:126-140

17. Kisacikoglu MC, Kesler M, Tolbert LM (2015) Single-phase onboard bidirectional PEV charger for V2G reactive power operation. IEEE Trans Smart Grid 6:767-775

18. Monteiro V, Pinto JG, Afonso JL (2016) Operation modes for the electric vehicle in smart grids and smart homes: present and proposed modes. IEEE Trans Veh Technol 65:1007-1020

19. Tashakor N, Farjah E, Ghanbari T (2017) A bidirectional battery charger with modular integrated charge equalization circuit. IEEE Trans Power Electron 32:2133-2145

20. Tran VT, Sutanto D, Muttaqi KM (2017) The state of the art of battery charging infrastructure for electrical vehicles: Topologies, power control strategies, and future trend. In: 2017 Australasian Universities Power Engineering Conference (AUPEC), Melbourne, VIC, 2017, pp. 1-6. doi: 10.1109/AUPEC.2017.8282421

21. Praneeth AVJS, Williamson SS (2018) A review of front end ACDC. In: 2018 IEEE transportation electrification conference and expo (ITEC), Long Beach, CA, 2018, pp 293-298. doi: 10.1109/ ITEC.2018.8450186

22. Koushki B, Safaee A, Jain P, Bakhshai A (2014) Review and comparison of bi-directional AC-DC converters with V2G capability for onboard EV and HEV. In: 2014 IEEE transportation electrification conference and expo (ITEC), Dearborn, MI, 2014, pp 1-6. doi: 10.1109/ITEC.2014.6861779

23. Na T, Yuan X, Tang J, Zhang Q (2019) A review of on-board integrated charger for electric vehicles and a new solution. In: 2019 IEEE 10th international symposium on power electronics for distributed generation systems (PEDG), Xi'an, China, 2019, pp 693-699. doi: 10.1109/PEDG.2019.8807565

24. Kumar S, Usman A (2018) A review of converter topologies for battery charging applications in plug-in hybrid electric vehicles. In: 2018 IEEE industry applications society annual meeting (IAS), Portland, OR, 2018, pp 1-9. doi: 10.1109/IAS.2018.8544609

25. Na T, Yuan X, Tang J, Zhang Q (2019) A review of onboard integrated electric vehicles charger and a new single-phase integrated charger. CPSS Trans Power Electron Appl 4(4):288-298. https://doi.org/10.24295/CPSSTPEA.2019.00027

26. Singh B, Singh BN, Chandra A, Al-Haddad K, Pandey A, Kothari DP (2004) A review of three-phase improved power quality ACDC converters. IEEE Trans Ind Electron 51:641-660

27. Soeiro TB, Friedli T, Kolar JW (2012) SWISS rectifier-a novel three-phase buck-type PFC topology for electric vehicle battery charging. In: IEEE Applied Power Electronics Conference and Exposition (APEC), pp 2617-2624
28. Bak Y, Lee E, Lee KB (2015) Indirect matrix converter for hybrid electric vehicle application with three-phase and single-phase outputs. Energies 8:3849-3866

29. Zou J, Wang C, Cheng H, Liu J (2018) Triple line-voltage cascaded VIENNA converter applied as the medium-voltage AC drive. Energies 11(5):1079-1094

30. Kwon Y-D, Park J-H, Lee K-B (2018) Improving line current distortion in single-phase Vienna rectifiers using model-based predictive control. Energies 11(5):1237-1258

31. Chelladurai J, Vinod B (2015) Performance evaluation of three phase scalar controlled PWM rectifier using different carrier and modulating signal. J Eng Sci Technol 10(4):420-433

32. Kedjar B, Kanaan HY, Al-Haddad K (2014) Vienna rectifier with power quality added function. IEEE Trans Ind Electron 61:3847-3856

33. Channegowda J, Pathipati VK, Williamson SS (2015) Comprehensive review and comparison of DC fast charging converter topologies: Improving electric vehicle plug-to-wheels efficiency. In: IEEE International Symposium on Industrial Electronics, pp 263-268

34. Dwari S, Parsa L (2010) An efficient AC-DC step-up converter for low-voltage energy harvesting. IEEE Trans Power Electron 25(8):2188-2199. https://doi.org/10.1109/TPEL.2010.2044192

35. Schrittwieser L, Leibl M, Haider M, Thöny F, Kolar JW, Soeiro TB (2019) 99.3\% efficient three-phase buck-type all-SiC SWISS rectifier for DC distribution systems. IEEE Trans Power Electron 34(1):126-140. https://doi.org/10.1109/TPEL.2018.2817074

36. Wang $Q$, Zhang $X$, Burgos $R$, Boroyevich $D$, White $A M$, Kheraluwala M (2018) Design and implementation of a two-channel interleaved vienna-type rectifier with $>99 \%$ efficiency. IEEE Trans Power Electron 33(1):226-239. https://doi.org/10.1109/ TPEL.2017.2671844

37. Hang L, Zhang M, Tolbert LM, Lu Z (2013) Digitized feedforward compensation method Vienna PFC converter. IEEE Trans Ind Electron 60:1512-1519

38. Wang L, Zhang D, Wang Y, Gu Y (2015) Dynamic performance optimization for high-power density three-phase Vienna PFC rectifier. In: 2015 IEEE 2nd international future energy electronics conference, pp 1-4

39. Dias JC, Lazzarin TB (2018) A family of voltage-multiplier unidirectional single-phase hybrid boost PFC rectifiers. IEEE Trans Ind Electron 65(1):232-241. https://doi.org/10.1109/TIE.2017.27219 19

40. Jia Q, Qi Y, Xiong X, Ma P (2018) Research and Implementation of SWISS rectifier based on fuzzy PI control. In: 2018 3rd international conference on mechanical, control and computer engineering (ICMCCE), Huhhot, 2018, pp 31-36. https://doi. org/10.1109/icmcce.2018.00015

41. Ahmed MA, Dasika JD, Saeedifard M, Wasynczuk O (2014) Interleaved SWISS rectifiers for fast EV/PHEV battery chargers. In: 2014 IEEE applied power electronics conference and exposition - APEC 2014, Fort Worth, TX, 2014, pp 3260-3265. doi: 10.1109/ APEC.2014.6803773

42. Zhang B, Xie S, Wang X, Qian Q, Zhang Z, Xu J (2019) Control scheme design for isolated SWISS-rectifier based on phaseshifted full-bridge topology. In: IEEE Applied power electronics conference and exposition (APEC), Anaheim, CA, USA, 2019, pp 2092-2096. doi: 10.1109/APEC.2019.8722189

43. Roy RB, Cros J, Basher E, Taslim SMB (2017) Fuzzy logic based matrix converter controlled induction motor drive. In: IEEE region 10 humanitarian technology conference (R10-HTC), Dhaka, 2017, pp 489-493. doi: 10.1109/R10-HTC.2017.8289005

44. Yilmaz M, Krein PT (2013) Review of battery charger topologies, charging power levels, and infrastructure for plug-in electric and 
hybrid vehicles. IEEE Trans Power Electron 28(5):2151-2169. https://doi.org/10.1109/TPEL.2012.2212917

45. Vahedi H, Labbe P, Al-Haddad K (2015) Single-phase singleswitch vienna rectifier as electric vehicle PFC battery charger. In: IEEE vehicle power and propulsion conference (VPPC), Montreal, QC, 2015, pp 1-6. doi: 10.1109/VPPC.2015.7353019

46. Anderson JA, Haider M, Bortis D, Kolar JW, Kasper M, Deboy G (2019) New synergetic control of a $20 \mathrm{~kW}$ isolated Vienna rectifier front-end ev battery charger. In: 20th workshop on control and modeling for power electronics (COMPEL), Toronto, ON, Canada, 2019, pp 1-8. doi: 10.1109/COMPEL.2019.8769657

47. Nguyen-Van T, Abe R, Tanaka K (2018) MPPT and SPPT control for PV-connected inverters using digital adaptive hysteresis current control. Energies 11:1-16

48. Al-Ogaili AS, Aris I, Bin Verayiah R, Ramasamy A, Marsadek M, Rahmat NA, Hoon Y, Aljanad A, Al-Masri AN (2019) A three-level universal electric vehicle charger based on voltage-oriented control and pulse-width modulation. Energies 12:2375

49. Zhang Y, Qu C (2015) Model predictive direct power control of PWM rectifiers under unbalanced network conditions. IEEE Trans Ind Electron 62:4011-4022

50. Chikouche Tarik Mohammed, Hartani Kada (2018) Direct power control of three-phase PWM rectifier based on new switching table. J Eng Sci Technol 13(6):1751-1763

51. Callaway DS, Hiskens IA (2011) Achieving controllability of electric loads. Proc IEEE 99:184-199

52. Callaway DS (2009) Tapping the energy storage potential in electric loads to deliver load following and regulation, with application to wind energy. Energy Convers Manag 50:1389-1400

53. Pontt J, Correa P, Rodríguez J, Member S, Pontt J, Member S, Silva CA (2007) Predictive current control of a voltage source predictive current control of a voltage source inverter. IEEE Trans Ind Electron 54:495-503
54. Rivera M, Yaramasu V, Rodriguez J, Wu B (2013) Model predictive current control of two-level four-leg inverters -Part ii: experimental implementation and validation. IEEE Trans Power Electron 28:1-9

55. Young HA, Perez MA, Rodriguez J (2014) Assessing finite-control-set model predictive control. IEEE Ind Electron Mag 8:44-52

56. Yaramasu V, Rivera M, Narimani M, Wu B, Rodriguez J (2014) Model predictive approach for a simple and effective load voltage control of four-leg inverter with an output LC filter. IEEE Trans Ind Electron 61:5259-5270

57. Jackson DK, Schultz AM, Leeb SB, Mitwalli AH, Verghese GC, Shaw SR (1997) A multirate digital controller for a 1.5-kW electric vehicle battery charger. IEEE Trans Power Electron 12:1000-1006

58. Chen Q, Luo X, Zhang L, Quan S (2017) Model predictive control for three-phase four-leg grid-tied inverters. IEEE Access 5:2834-2841

59. Bajracharya C, Molinas M, Suul JA, Undeland TM (2008) Understanding of tuning techniques of converter controllers for VSCHVDC. Nordic workshop on power and industrial electronics, June 9-11

60. Kolar JW, Ertl H, Zach FC (1996) Design and experimental investigation of a three-phase high power density high-efficiency unity power factor PWM (VIENNA) rectifier employing a novel integrated power semiconductor module. In: Proceeding of IEEE APEC'96 2, pp 514-523

61. Thandapani T, Karpagam R, Paramasivam S (2016) Comparative study of Vienna rectifier topologies. Int J Power Electron 7:147

Publisher's Note Springer Nature remains neutral with regard to jurisdictional claims in published maps and institutional affiliations. 